\title{
Bone strain gradients and optimization in vertebrate skulls
}

\author{
Callum F. Ross ${ }^{1}$ and Keith A. Metzger ${ }^{2}$ \\ ${ }^{1}$ Organismal Biology and Anatomy, University of Chicago, 1027East 57 St. Chicago IL \\ 60637, USA \\ ${ }^{2}$ Anatomical Sciences, Stony Brook University, Academic Tower A, T-8, \\ Stony Brook NY 11794-8081, USA
}

\begin{abstract}
Summary. It is often stated that the skull is optimally designed for resisting feeding forces, where optimality is defined as maximum strength with minimum material. Running counter to this hypothesis are bone strain gradients - variation in bone strain magnitudes across the skull - which in the primate skull have been hypothesized to suggest that different parts of the skull are optimized for different functions. In this paper strain gradients in the skulls of four genera of primates, Sus, and Alligator were documented and compared. Strain gradients were pervasive in all taxa sampled. Patterns of strain gradients showed inter-taxon differences, but strains in the mandible and zygomatic arch were always higher than those in the circumorbital and neurocranial regions. Strain magnitudes in Alligator were twice as high as those in mammals. Strain gradients were also positively allometric; i. e., larger primates show steeper gradients (larger differences) between the mandible and circumorbital region than smaller primates. Different strain magnitudes in different areas of the same animal are hypothesized to reflect optimization to different criteria. It is therefore hardly surprising that the skull, in which numerous functional systems are found, exhibits very steep gradients. Inter-specific differences in strain magnitudes at similar sites also suggest inter-specific differences in optimality criteria. The higher strain magnitudes in the Alligator skull suggest that the Alligator skull may be designed to experience extremely high strains less frequently whereas the primate skull may be designed to resist lower strains more frequently.
\end{abstract}

Key words: Mastication - Feeding - Skull - Mandible Primates - Crocodilians - Mammals

Correspondence to: C. F. Ross

E-mail: rossc@uchicago.edu

\section{Introduction}

In 1991, Hylander and colleagues reported that bone strain magnitudes recorded from the supraorbital regions of macaques and baboons are much lower than those recorded from the zygomatic arch, anterior root of the zygoma and mandibular corpus. They interpreted these data to suggest that the supraorbital tori of macaques and baboons could be greatly reduced in size while still maintaining an adequate safety factor to failure under routine masticatory loads. They concluded (Hylander et al. 1991) that their data provide "no good reason to believe that enlarged browridges in living and/or fossil primates are structural adaptations to counter powerful masticatory forces". Instead, they hypothesized that when the orbits are positioned well rostral to the brain, they must be protected by sufficient bone to "prevent structural failure due to relatively infrequent non-masticatory external forces associated with highly active primates (e.g., traumatic accidental forces applied to the orbits and neurocranium)" (Hylander et al. 1991; see also Hylander and Ravosa 1992).

In a later paper, Hylander and Johnson (1997) reported that strain magnitudes also vary within the zygomatic arch, being higher anteriorly than posteriorly. They argued that if optimality is defined as maximum strength with minimum material, the extreme variability in bone strain magnitudes across the facial skeleton falsifies the general assumption that the facial skeleton is optimized for resisting forces generated during routine mastication. They reiterated the hypothesis that bone mass in excess of that needed to optimize the facial skeleton to resist masticatory forces may make the facial bones "structurally adapted to counter infrequent nonmasticatory traumatic loads" (Hylander and Johnson 1997). 
Subsequent work demonstrated that bone strain magnitudes are also low in the supraorbital regions and intermediate in the lateral orbital walls of owl monkeys and galagos (Ross and Hylander 1996; Ravosa et al. 2000 a). Ravosa et al. (2000 a) reiterated the hypothesis that excess bone mass in the facial skeleton (in this case, the lateral orbital wall) functioned "to ensure an adequate safety factor for accidental nonmasticatory forces"; they also suggested that there might be "positive allometry of the strain gradient" in the primate face, with larger animals having lower strains in the supraorbital region because of the positive allometry of circumorbital structures observed in morphometric analyses (Moss and Young 1960; Shea 1986; Ravosa 1988, 1991 a-c).

Observations in owl monkeys, macaques and galagos of low strain magnitudes along the medial orbital walls, orbital roofs and postorbital septa, thin plates of bone where traumatic blows were unlikely to fall, suggested to Ross (2001) that not all strain gradients reflect selection for increased resistance to traumatic blows to the head; he suggested a range of functions for thin plates of circumorbital bone that experience very low strain magnitudes, including providing a rigid support for the brain and its meninges, deflecting chewing muscles around the orbital contents, and providing attachment for chewing muscles. Ross (2001) concluded that, "[a]ny role that these thin circumorbital bony plates perform in resisting feeding forces is coincidental and insignificant, and could be better performed by a more efficient distribution of bony tissue".

In sum, Hylander, Johnson, Ravosa and Ross have argued that the primate facial skeleton is not optimally designed for resisting forces generated during feeding because its various components perform a range of functions. Adaptations of the skeleton to these functions include distributions of bone mass and bone shapes that are over-designed for resisting routine masticatory stresses: hence bone strain magnitudes recorded from these regions during routine mastication are low.

These hypotheses regarding variations in strain magnitude (strain gradients) in primate skulls run counter to a long tradition in craniofacial biomechanics that the face is optimized for resisting masticatory loads (see references in Hylander and Johnson 1997; Preuschoft et al. 1986 a,b). This tradition persists in recent presentations of finite-element analyses of human skull morphology (Witzel and Preuschoft 1999, 2002); "Since we have found a far-reaching correspondence between the spatial arrangement of stress-bearing regions and the bony structure of the skull, the conclusion seems justified that the shape of the skull is essentially caused by biomechanic necessities. Characteristic for all parts is a light-weight construction optimised for minimal mass and maximal strength with the best possible approach to minimal areas around given volumes" (Witzel and Preuschoft 2002).

Published and new bone strain data relevant to these hypotheses are presented here and the following questions are addressed: How pervasive are strain gradients - variation in strain magnitudes - within the vertebrate skull? Are strain gradients similar from one species to another? What do strain gradients tell us about craniofacial
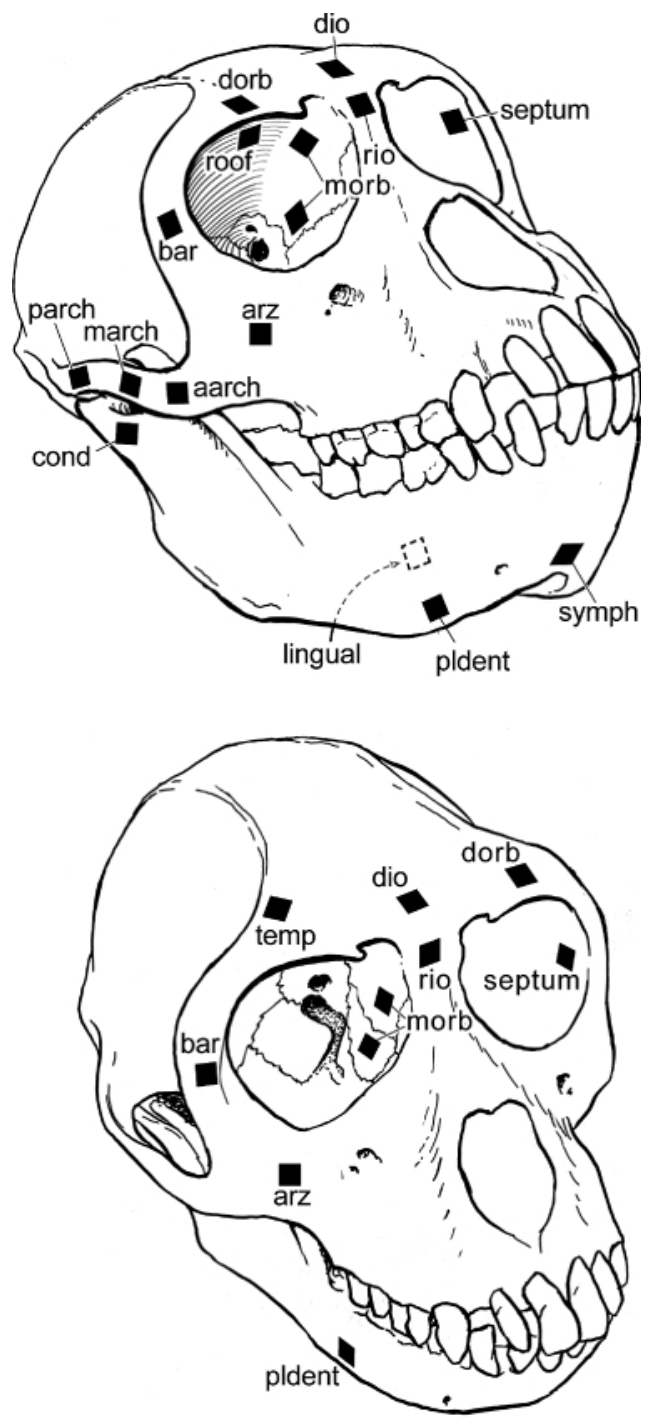

Fig. 1. Diagram of skull of Macaca illustrating gauge locations in primates and Sus. Abbreviations and region groups: Neurocranium, pariet, parietal, Sus only; temp, adjacent to temporal line on frontal bone, Macaca only; Orbital region, dio, dorsal interorbital; rio, rostral interorbital; dorb, dorsal orbital; roof, orbital roof; bar, postorbital bar (anterior surface in Macaca, lateral surface in Eulemur, Otolemur and Aotus); septum, postorbital septum (intraorbital surface), morb, medial orbital wall; Zygomatic Arch, aarch, anterior 1/3 of zygomatic arch (Macaca only);

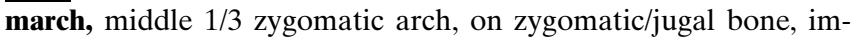
mediately anterior to zygomatico-temporal suture; parch, posterior arch on zygomatic process of squamous part of temporal bone; zflg, zygomatic flange (Sus only); arz, anterior root of zygoma, infraorbital of Hylander et al. 1991; Snout, max, maxilla; na, nasal (Sus only); pmax, premaxilla; Jaw Joint; qjug, quadratojugal; quad, quadrate; cond, surangular in Alligator, condylar neck in Sus and Macaca; Mandible, symph, symphysis; avdent, anterior ventral dentary; pvdent, posterior ventral dentary; aldent, anterior lateral dentary; pldent, posterior lateral dentary; ang, angular; lingual, splenial in Alligator, lingual aspect of mandibular corpus in Macaca. 
adaptation and evolution? To address these questions the available data on bone strain magnitudes in vertebrate skulls are reviewed, characteristics of the strain gradients in different taxa are compared, and theoretical issues regarding the meaning of these gradients are addressed.

\section{Materials and methods}

Sufficient data for an analysis of strain gradients are only available for a limited number of species. The primate data are analyzed at the generic level to increase the number of sites sampled within each taxonomic unit and to increase the number of experiments on any one site. Data on genus Macaca are pooled from M. fascicularis and M. mulatta (Hylander 1979a, 1985; Hylander et al. 1991; Dechow and Hylander 2000; Hylander and Johnson 1997; Ross 2001, unpublished data). The data from Aotus come from three individuals of unknown species (Ross and Hylander 1996; Ross 2001). The data for Otolemur come from experiments on one adult $O$. garnetti, two adult male (Ravosa et al. 2000 a) and one adult female $O$. crassicaudatus (Ross 2001). Data are also available from numerous individuals of min-
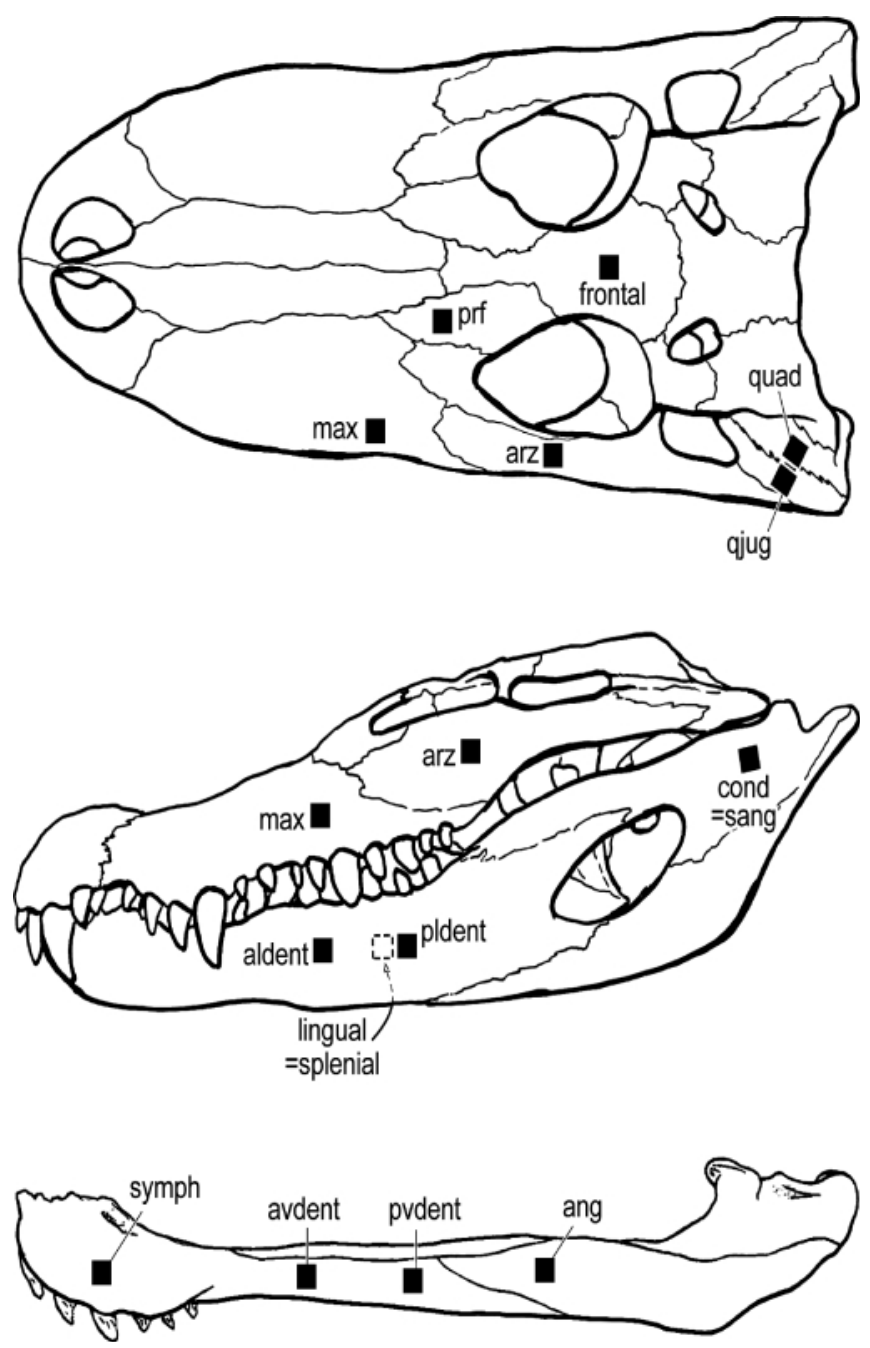

Fig. 2. Diagram of skull of Alligator illustrating gauge locations. Abbreviations in Figure 1.
Table 1. Mean and peak $\gamma$-max data.

\begin{tabular}{|c|c|c|c|}
\hline Species & Gauge location & $\begin{array}{l}\text { Mean } \\
\gamma \text {-max }(\mu \varepsilon)\end{array}$ & $\begin{array}{l}\text { Peak } \\
\gamma \text {-max }(\mu \varepsilon)\end{array}$ \\
\hline \multirow[t]{6}{*}{ Eulemur } & dorsal interorbital & 100 & 256 \\
\hline & dorsal orbital & 109 & 296 \\
\hline & postorbital bar & 284 & 676 \\
\hline & zygomatic arch (middle) & 530 & 1277 \\
\hline & anterior root of zygoma & 405 & 1420 \\
\hline & mandibular corpus & 599.5 & \\
\hline \multirow[t]{4}{*}{ Otolemur } & dorsal interorbital & 334 & 1221 \\
\hline & postorbital bar & 398 & 1320 \\
\hline & medial orbital wall & 346 & 609 \\
\hline & mandibular corpus & 1301 & 2653 \\
\hline \multirow[t]{5}{*}{ Aotus } & dorsal interorbital & 143 & 654 \\
\hline & postorbital bar & 532 & 1690 \\
\hline & medial orbital wall & 160 & 1294 \\
\hline & postorbital septum & 210 & 740 \\
\hline & mandibular corpus & 977 & 2333 \\
\hline \multirow[t]{16}{*}{ Macaca } & dorsal interorbital & 183 & 651 \\
\hline & rostral interorbital & 90.5 & 270 \\
\hline & dorsal orbital & 85.25 & 375 \\
\hline & postorbital bar & 188 & 917 \\
\hline & postorbital septum & 48 & 256 \\
\hline & orbital roof & 111 & 332 \\
\hline & medial orbital wall & 58 & 657 \\
\hline & anterior root of zygoma & 701 & 1655 \\
\hline & anterior arch & 1194.5 & 3417 \\
\hline & middle arch & 704.25 & 2592 \\
\hline & posterior arch & 340 & 768 \\
\hline & mandibular corpus & 497.6 & $1679 / 2564$ \\
\hline & lingual mandible & 300 & 630 \\
\hline & mandibular symphysis & 389 & 2512 \\
\hline & temporal line & 302 & 1014 \\
\hline & subcondylar region & 207 & 1376 \\
\hline \multirow[t]{14}{*}{ Alligator } & anterior ventral dentary & 2107 & 5935 \\
\hline & posterior ventral dentary & 1073 & 2928 \\
\hline & anterior lateral dentary & 1415 & 4204 \\
\hline & posterior lateral dentary & 3683 & 5934 \\
\hline & symphysis & 961 & 2019 \\
\hline & angular & 430 & 1100 \\
\hline & surangular & 2162 & 6488 \\
\hline & splenial & 787 & 1650 \\
\hline & quadratojugal & 1087 & 3920 \\
\hline & quadrate & 644 & 1194 \\
\hline & midline dorsal interorbital & 893 & 1767 \\
\hline & prefrontal & 1090 & 4434 \\
\hline & anterior root of zygoma & 2316 & 4973 \\
\hline & lateral maxilla & 1620 & 4269 \\
\hline \multirow[t]{9}{*}{ Sus } & frontal & 76 & \\
\hline & parietal & 65 & \\
\hline & $\begin{array}{l}\text { posterior zygomatic } \\
\text { (outer squamosal) }\end{array}$ & 981 & \\
\hline & $\begin{array}{l}\text { middle zygomatic } \\
\text { (zygomatic flange) }\end{array}$ & 277 & \\
\hline & all maxilla mean & 379 & \\
\hline & premaxilla & 130 & \\
\hline & nasal & 67 & \\
\hline & mandibular corpus & 213 & \\
\hline & mandibular condylar process & 375 & \\
\hline
\end{tabular}




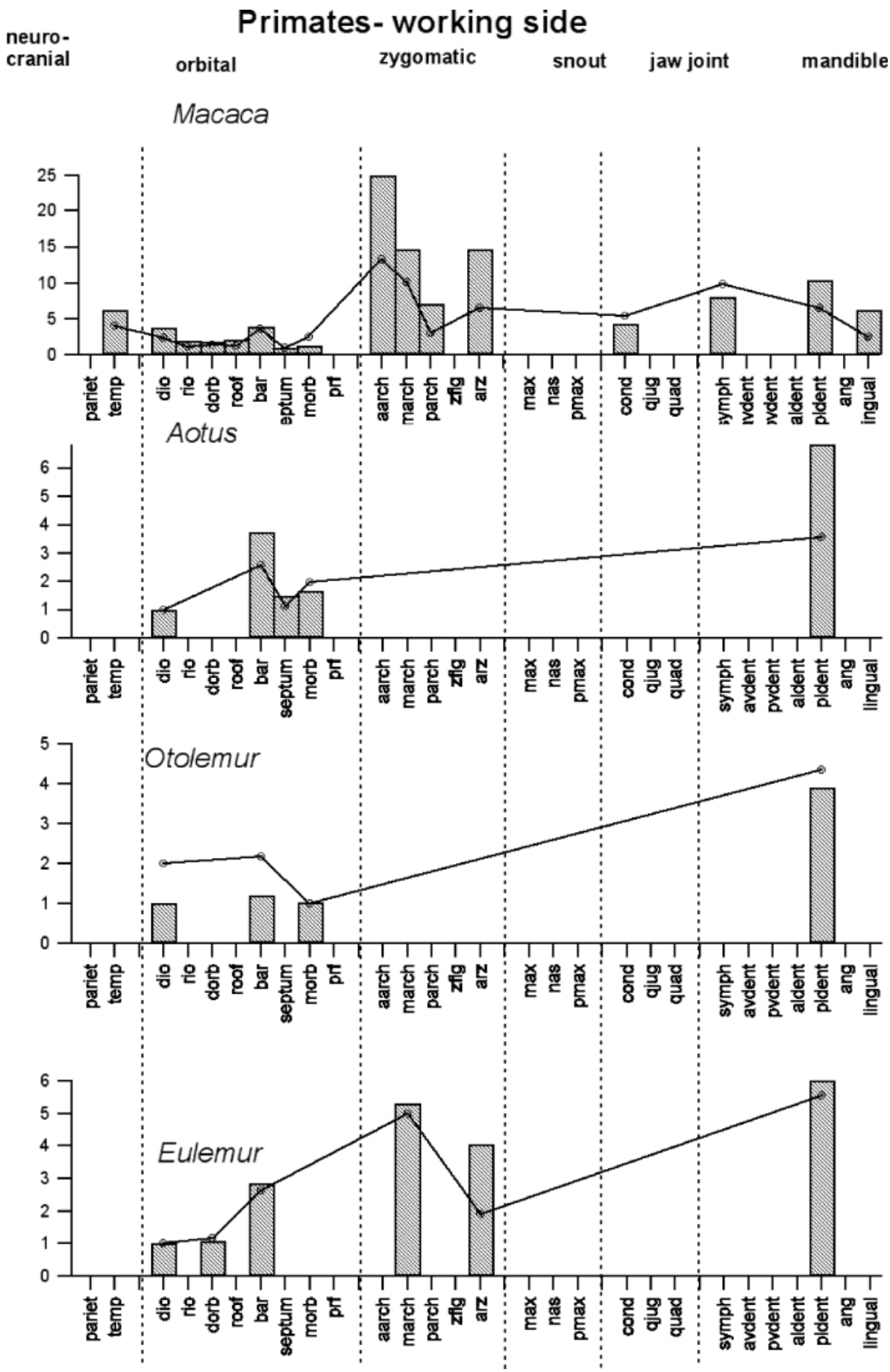

Fig. 3A.

iature pigs, Sus scrofa (Herring and Teng 2000; Herring et al. 1996, 2001; Rafferty et al. 2000) and two Alligator mississipiensis (Ross and Metzger, unpublished data).

Strain $(\varepsilon)$, a dimensionless unit equaling the change in length of an object divided by its original length, is measured in microstrain $(\mu \varepsilon)$ units, equal to $1 \times 10^{-6}$. The maximum principal strain $\left(\varepsilon_{1}\right)$ is usually the largest tensile strain value, while the minimum principal strain is usually the largest compressive strain value $\left(\varepsilon_{2}\right) \cdot \varepsilon_{1}-\varepsilon_{2}$ is equal to the absolute maximum shear strain, or $\gamma$ max (Hylander 1979 a; Hibbeler 2000). Different loading regimes can be associated with differences in relative principal strain magnitudes (e.g., Hylander et al. 1991; Ross and Hylander 1996). For example, a bony member subjected primarily to axial compressive loading will have high magnitudes of $\varepsilon_{2}$, while a bone subjected primarily to tension will experience high values of $\varepsilon_{1}$. To enable comparisons of strain magnitudes across sites with different loading regimes, we use $\gamma$-max values to compare levels of overall strain (Hylander et al. 1991; Ravosa et al. 2000 a).

Mean and peak $\gamma$-max values at a range of sites (Fig. 1 and 2) were collected from the literature and from our data files (Tab.1). All workers report mean values of either $\gamma$-max or $\varepsilon_{1}$ and $\varepsilon_{2}$ for each experiment or each animal. When mean $\gamma$-max values were not given, they were estimated from mean values of $\varepsilon_{1}$ and $\varepsilon_{2}$. When peak $\gamma$-max values were not reported (Dechow and Hylander 2000), the maximum values of $\varepsilon_{1}$ and $\varepsilon_{2}$ re- 


\section{Nonprimates- Working side}

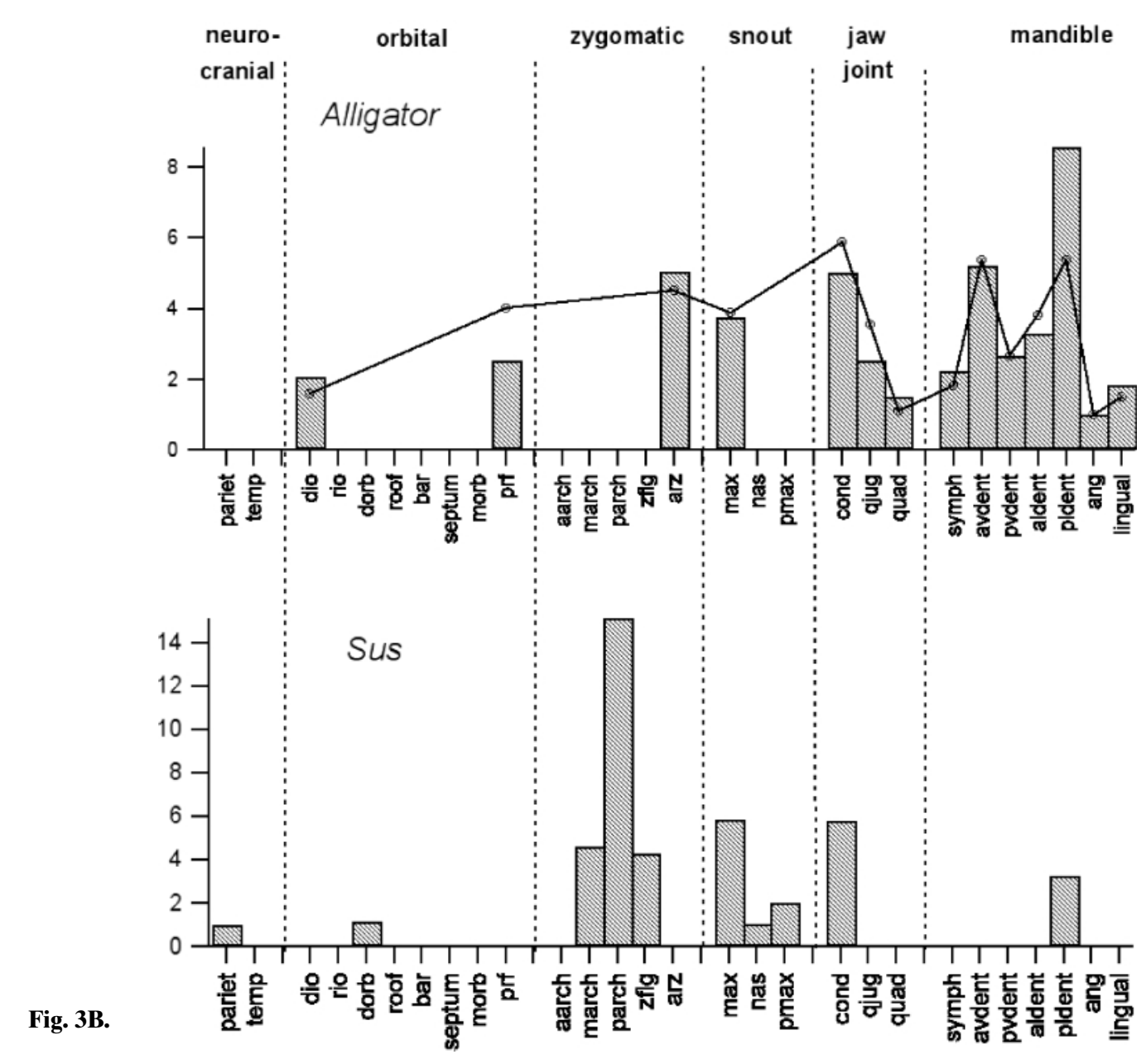

Fig. 3. A. Bar plots of standardized mean $\gamma$-max strains and line plots of standardized peak $\gamma$-max strains recorded from all sites in primates. Square boxes in Macaca and Otolemur plots are transducer-biting data. Abbreviations for sites are given in Figure 1. B. Bar plots of standardized mean $\gamma$-max strains and line plots of standardized peak $\gamma$-max strains recorded from all sites in Sus and Alligator. Alligator data are transducer-biting data; Sus data are mastication data. Abbreviations for sites are given in Figures 1 (Sus) and 2 (Alligator).

corded during a single experiment were used to estimate peak $\gamma$-max. In the case of the data from the pigs, neither $\gamma$-max nor maximum $\varepsilon_{1}$ and $\varepsilon_{2}$ data were available, so peak $\gamma$-max data are not presented (Herring and Teng 2000; Herring et al. 1996, 2001; Rafferty et al. 2000). The primate and pig mean $\gamma$-max values were calculated using only working-side mastication data, pooling data from all food types. All alligator data are from unilateral biting on a bite force transducer. The grand mean $\gamma$ max for any specific gauge was calculated using unweighted mean values of working-side $\gamma$-max reported for each experiment or animal. Peak $\gamma$-max values for each gauge included all food types, chew sides, experiments and investigators. Raw data are presented in Table 1. The strain data in Figure 3 are standardized within each taxon by assigning the lowest mean $\gamma$-max and the lowest peak $\gamma$-max values of 1.0 and scaling the mean and peak $\gamma$-max at other sites in a linear fashion. Standardizing in this manner facilitates comparison of patterns of gradients within and across taxa
Simultaneous strains are those recorded during a single experiment where multiple strain gauges are used at the same time to record strain magnitudes from more than one location (Hylander et al. 1991; Hylander and Johnson 1992). Such data arguably provide a more precise representation of the differences in strain magnitude between regions of the skull. However, simultaneously recorded strains are not presented in most studies, so non-simultaneously recorded strain data must be used (Hylander et al. 1991; Hylander and Johnson 1992).

The effect of using non-simultaneous strains to calculate strain gradients was evaluated by comparing ratios of strain magnitudes calculated from simultaneous and non-simultaneous strain data. The ratio of simultaneous $\gamma$-max mandibular corpus to $\gamma$-max postorbital bar strains ranges from 1.32 to 6.88 , with the means ranging from 2.23 to 3.91. Mean non-simultaneous ratios all fell within the overall range of ratios calculated from the simultaneous data, although they underestimate the ratios calculated from simultaneous data. Similar results were obtained when esti- 
mating ratios of zygomatic arch strain to corpus strain. Ratios calculated from non-simultaneous data collected from areas with lower strain are less accurate, although the ratios in these low strained areas are more variable in the simultaneous data.

To evaluate Ravosa et al.'s (2000 a, b) hypothesis of "positive allometry" of strain gradients, a ratio is calculated of the highest strains in the mandibular corpus to the lowest strains in the rest of the skull. This ratio was then plotted against skull length. Data from the zygomatic region are not included in this calculation because data from this region are not available for all taxa.

\section{Results}

The grand mean and peak $\gamma$-max reported or recorded at each site in the skull are given in microstrain $(\mu \varepsilon)$ units in Table 1. There was a close correlation between peak $\gamma$-max strains and mean $\gamma$-max strains in all taxa (r's: Eulemur .921; Otolemur .939; Macaca .891; Alligator .842; Aotus .953), and the data for all taxa lie on the same trajectory. Using either mean or peak $\gamma$-max to document strain gradients yields similar results and these results are broadly comparable across taxa.

The highest strain magnitudes were recorded during transducer biting in Alligator, in which 14 sites were sampled. All sites in Alligator experienced peak $\gamma$-max greater than $1000 \mu \varepsilon$, with the lowest peak values recorded from the angular $(1100 \mu \varepsilon)$. The highest peak $\gamma$-max strains recorded in Alligator are among the largest reported for vertebrates. Values from seven of the sites exceed $4000 \mu \varepsilon$, with the surangular experiencing $\gamma$-max strains over $6400 \mu \varepsilon$, and the ventral and lateral dentary sites experiencing $\gamma$-max strains over $5900 \mu \varepsilon$. The lowest strains in Alligator were recorded from the angular.

The best-sampled genus is Macaca (16 sites). The highest strains were recorded in the anterior part of the zygo- matic arch and anterior root of the zygoma (infraorbital region of Hylander et al. 1991), followed by the mandible sites. The circumorbital and neurocranial regions experience relatively low mean $\gamma$-max strains. In Eulemur, both mean and peak zygomatic strains are similar to those from the mandible, with lower strains recorded from the supraorbital sites and the postorbital bar. In Aotus, Otolemur and Eulemur, strains in the circumorbital region are lower than those in the mandible, and, like Macaca, the highest strains in the circumorbital region are from the postorbital bar. The highest strains reported for any mammal in this sample were $3788 \mu \varepsilon$ recorded from the lateral surface of the mandibular corpus in Otolemur during transducer biting. Peak $\gamma$-max strains are not available for Sus, but the highest mean $\gamma$-max strains were only $980 \mu \varepsilon$, recorded from the posterior zygomatic arch. Anteriorly on the arch, on the zygomatic flange, and on the condylar neck, strains between $300 \mu \varepsilon$ and $400 \mu \varepsilon$ were recorded. Elsewhere, mean $\gamma$-max strains strains were lower.

The steepest gradient (i.e., greatest range of strain magnitudes) in both mean and peak $\gamma$-max strains was seen in Macaca, followed by Sus, Alligator, Aotus, Eulemur, and Otolemur. The steepest gradients were seen in the best-sampled mammals, Macaca (16 sites), and Sus (10 sites), and the well sampled Alligator (14 sites), with lower gradients in Eulemur (6 sites), Aotus (5 sites) and Otolemur (4 sites). This reflects a sampling inequity that might bias attempts to compare gradients across taxa. Excluding data from the zygoma, Ravosa et al.'s allometry hypothesis was evaluated by using the same sites in multiple taxa. Figure 4 plots against skull length the ratio of highest mandibular strains to lowest cranial strains. Among primates, larger taxa had steeper gradients than smaller animals, and Alligator had a less steep strain gradient than expected for a primate of its head size.

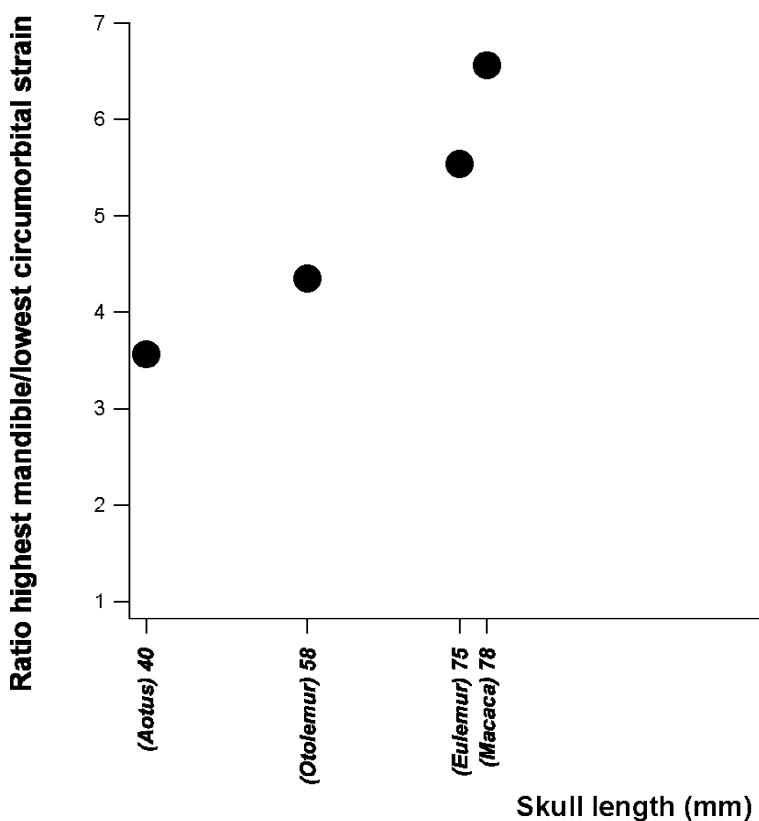

Fig. 4. $\gamma$-max in the mandible/lowest peak $\gamma$-max in the circumorbital region against skull length (mm). 


\section{Discussion and Conclusions}

Bone strain gradients are natural consequences of variation in the position and/or properties of bony material relative to the bending or twisting axis of the structure it is part of. Stress and strain are only uniform across a structure's cross-section and along its length if it is of uniform cross-section and material properties and is either loaded axially in pure tension or pure compression, or is loaded in pure shear. In structures under torsion, stresses and strains increase with distance from the twisting axis; in structures under bending, stresses and strains increase with distance from the bending axis, and in structures under shear, non-uniform cross-sectional geometry produces concentrations in shear flow (Hibbeler 2000). Bones that are optimized (optimality is defined as maximum strength with minimum material) for strength under torsion or bending will have bone located as far from the bending or twisting axes as possible, minimizing strain gradients as a result.

Nevertheless, bone stresses and strains will never be entirely constant because even in the most optimally designed bones it is impossible to have infinitely thin walls. Consequently, strains vary across long bone cross-sections in various mammals, including dogs (Carter et al. 1981), horses (Rybicki et al. 1977) and primates (Demes et al. 1998). Moreover, there is good evidence that long bone cross-sectional geometry is not always optimized for strength. Rather Currey and Alexander (1985) found that long bone cross-sectional geometry reflects optimization for a range of functions: strength under bending or impact loading, fatigue resistance or stiffness and buoyancy control (Currey 2002). Given this range of mechanical functions for vertebrate long bones, it is inevitable that bone strain magnitudes in the postcranial skeleton will vary markedly from place to place and from taxon to taxon.

The available data indeed reveal bone strain gradients within and between long bones (Hsieh et al. 2001). In Alligator during fast locomotion, the mean peak $\gamma$-max strains in the femur are 1.6 times higher than those recorded from the tibia (Blob and Biewener 1999) and, in Ovis, normal strains in the metatarsal are 1.5-1.7 times higher than those recorded from the tibia (Lieberman et al. 2003). Moreover, there is evidence that strain gradients might actually be preferred over equivalent strains and equivalent strength. Lieberman et al. (2003) found that in growing sheep subjected to exercise, midshafts of proximal limb elements (tibiae) experienced lower strains and higher rates of periosteal remodeling relative to distal limb elements (metatarsals), which experienced higher strains and higher rates of Haversian remodeling. They hypothesized that Haversian remodeling predominates in distal limb elements to avoid adding bone mass distally where it is energetically costly to move during locomotion. These data suggest that differing bone strain magnitudes in different limb elements are indicative of optimization to different functional criteria.
The data presented here reveal strain gradients in all tetrapod skulls that have been adequately sampled. This includes five genera of primates, one nonprimate mammal (Sus), and Alligator. In vivo bone strain gradients, albeit less well documented, have also been reported in the skull of the baboon Papio (Hylander et al. 1991), the sheep Ovis (Thomason et al. 2001), and the hyrax (Lieberman et al. 2004); Buckland-Wright (1978) reports in vitro strain gradients in dry cat skulls during loading and in anaesthetized cats during muscle stimulation. Together, these data suggest that bone strain gradients are pervasive in tetrapod skulls and cannot be invoked as evidence for specific feeding behaviors (e. g., Rayfield et al. 2001).

There is also evidence of similarities in patterns of strain gradients between the tetrapod skulls examined here: strains tend to be highest in the mandible and/or the zygomatic region and lowest on the neurocranium and around the orbits. Within the circumorbital region of primates, strains on the postorbital bar are higher than those on the medial orbital wall or supraorbital region. In primates and alligators, strains on the lingual face of the mandible are lower than those on the lateral face.

If strain gradients in the skull are indicative of optimality to different criteria in different places, then the mandible and zygoma are more optimized to different criteria than the circumorbital region and neurocranium (Hylander et al. 1991; Hylander and Johnson 1997; Ravosa et al. 2000 a; Ross 2001). The strain data presented here were collected during feeding, so the high strain magnitudes suggest closer optimality of the mandible and zygoma to feeding forces. Closer optimality of the mandible to feeding forces is also suggested by the high in vivo bone strain magnitudes recorded from the mandibles of a range of nonprimate mammals (opossums, Crompton 1995; rabbits, Weijs and De Jong 1977; dogs, Kakudo et al. 1973), and by the many aspects of mandibular and dental morphology in extant and fossil mammals related to loading regimes deduced from in vivo studies (e.g., Bicknevicius and Ruff 1992; Bouvier 1986; Bouvier and Hylander 1996; Daeglin 2001, 2002; Jenkins et al. 2002; Herring and Liu 2000; Hogue and Ravosa 2001; Hylander 1979 a, b, 1985, 1988; Hylander and Bays 1979; Hylander and Johnson 1992; Liu and Herring $2000 \mathrm{a}, \mathrm{b}$; Ravosa 1990, 1991 a, b, 1996; Vinyard and Ravosa 1998; Wolff 1984). This hypothesis is also supported by Thomason's demonstration that the carnivoran mandible is better optimized for resisting feeding forces than the cranium (Thomason 1991). In addition, although bone strain data from the tetrapod rostrum are scant, crocodilians resemble mammals in their patterns of optimization, with the cross-sectional distribution of bony material in their mandible and rostrum being suggestive of fairly evenly distributed stresses under bending, torsion and shear, with decreased stresses in the back of the rostrum, around the orbits, and in the braincase (van Drongelen and Dullemeijer 1982; Preuschoft et al. $1986 \mathrm{a}, \mathrm{b}$ ). The low optimality of cranial shape around the orbits is matched by low strain magnitudes through this region. 
Despite general similarities across Alligator and mammals in bone strain gradients, there is variation in the details. For example, in Macaca, strains are highest at the anterior extremity of the zygomatic arch, and decrease posteriorly, whereas in Sus and Felis, strains are lowest in the anterior part of the arch and increase posteriorly (Fig. 3) (Buckland Wright 1978; Herring et al. 1996). Mean $\gamma$-max strains on the frontal bone of Ovis $(583 \mu \varepsilon)$ are higher than those estimated on the maxilla $(214 \mu \varepsilon)$ (Thomason et al. 2001), whereas the reverse is true in Sus and Alligator. This variation supports the suggestion that strain gradients differ between animals with different skull designs (Ravosa et al. 2000 a).

Aspects of design likely to produce these differences are overall size (Ravosa et al. 2000 a), local geometry, material properties, and the nature and magnitude of external forces. The influence of overall (or even just facial) size on strain gradients is corroborated by the data presented here: larger animals exhibit steeper gradients than smaller ones (Fig. 4). These size-related changes in strain gradients during feeding might reflect adaptive changes to increased forces exerted during other activities; i.e., forces experienced during traumatic blows to the head scale positively relative to forces exerted during feeding. Alternately, they might merely reflect nonadaptive consequences of increasing relative size of the face. Implicit in the first case is the hypothesis that natural selection favors upper facial bones that are over-designed for feeding because they confer a benefit under assault. The second case posits that increased robusticity of upper facial bones is a pleiotropic effect of selection for positive allometry of facial size, and that it is not detrimental enough in terms of energy expenditure, or is too tightly linked to be selected against. More succinctly, the first case posits size related differences in what skulls are optimized for (the nature of optimality), whereas the second posits size related differences in how well skulls are optimized (the degree of optimality). In either case, the positive allometry of the strain gradient implies that smaller animals will have skulls more closely optimized for resisting feeding forces than larger animals.

Estimates of mandibular strength derived from crosssectional geometry also suggest taxonomic differences in the nature or degree of optimality, with primate mandibles being differently or less well optimized for resisting feeding forces than those of carnivores (Bicknevicius and Ruff 1992; Daegling 1993; Daegling and Hotzman 2003). One possibility is that the jaws of carnivores are optimized to resist higher external forces during feeding than those of frugivorous primates. These forces, generated while subduing large prey or breaking into hard skeletal material (Bicknevicius and Ruff 1992) would result in routinely higher strains in the mandible during feeding. Primates, in contrast, might be optimized to resist fatigue loading at lower strain levels, and so would routinely experience lower strains during feeding, but would chew many more times during a day than a carnivore.
Clearly long term in vivo strain data from carnivores and primates are needed to evaluate this hypothesis; the currently available strain data from Alligator, however, provide some support for it (Tab. 1). Across nine separate experiments on two different alligators, mean $\gamma$-max strain magnitudes in Alligator are always at least twice and usually three times higher than strains recorded from comparable sites in the mammals examined here. This result is robust even when taking into account the fact that the mammal data presented here were recorded during mastication, whereas the Alligator data were all recorded during transducer biting. Maximum strain magnitudes recorded from mandibles of mammals (Macaca, $2564 \mu \varepsilon$; Otolemur, $3788 \mu \varepsilon$ ) during transducer-biting fall well below the maximum values recorded from alligators (anterior dentary $4204 \mu \varepsilon$, posterior dentary $5934 \mu \varepsilon$ ). These data suggest that either the mandibles of primates are much less well optimized than those of Alligator, or Alligator and primate mandibles are optimized according to different criteria. Optimality for fatigue loading in primates might explain this difference.

Optimality for fatigue loading might also explain the low strain magnitudes (mean $\gamma$-max tibia, $752 \mu \varepsilon$, femur, $1245 \mu \varepsilon$ ) in the Alligator postcranial skeleton (Blob and Biewener 1999) relative to the cranial strains reported here. If low strain magnitudes in the postcranium do compensate for the lower remodeling rates in "reptilian" bone (Enlow 1969; de Ricqles 1975), as suggested by Blob and Biewener (1999), then the high strain magnitudes in the Alligator skull must occur very infrequently to avoid fatigue fractures (Lanyon et al. 1982; Currey 1984; Burr et al. 1985; Nunamaker et al. 1990; Davies et al. 1993).

Acknowledgements. CFR thanks Thomas Koppe and Todd Rae for the kind invitation to the conference in Greifswald, and Holger Preuschoft and Hermann Prossinger for many stimulating discussions. Luci Betti prepared some of the illustrations; D. Daegling, S. Herring, W. Hylander, R. Blob and M. Ravosa provided useful comments on the manuscript. This research was supported by NSF Physical Anthropology 9706676, 0109130. This is Duke University Primate Center publication number 784 .

\section{References}

Biknevicius AR, Ruff CB (1992) The structure of the mandibular corpus and its relationship to feeding behaviors in extant carnivorans. J Zool Lond 228: 479-507

Blob RW, Biewener AA (1999) In vivo locomotor strain in the hindlimb bones of Alligator mississippiensis and Iguana iguana: implications for the evolution of limb bone safety factor and non-sprawling limb posture. J Exp Biol 202: 1023-1046

Bouvier M (1986) A biomechanical analysis of mandibular scaling in Old World monkeys. Am J Phys Anthropol 69: 473-482

Bouvier M, Hylander WL (1996) The mechanical or metabolic function of secondary osteonal bone in the monkey Macaca fascicularis. Archs Oral Biol 41: 941-950

Buckland-Wright JC (1978) Bone structure and the patterns of force transmission in the cat skull (Felis catus). J Morphol 155: $35-62$ 
Burr D, Martin R, Schaffler M, Radin E (1985) Bone remodeling in response to in vivo fatigue microdamage. J Biomech 202: 99-127

Carter DR, Harris W, Vasu R, Caler W (1981) The mechanical and biological response of cortical bone to in vivo strain histories. In: Cowin SC (Ed) Mechanical Properties of Bone (AMD vol. 45). American Society of Mechanical Engineers: New York, pp 81-92

Crompton AW (1995) Masticatory function in nonmammalian cynodonts and early mammals. In: Thomason JJ (Ed) Functional Morphology in Vertebrate Paleontology. Cambridge University Press: New York, pp 55-75

Currey J (1984) The mechanical adaptations of bones. Princeton University Press: Princeton, New Jersey

Currey JD (2002) Bones: Structure and Mechanics. Princeton University Press: Princeton, New Jersey

Currey JD, Alexander RM (1985) The thickness of the walls of tubular bones. J Zool Lond 206: 453-468

Daegling DJ (1993) The relationship of in vivo bone strain to mandibular corpus morphology in Macaca fascicularis. J Hum Evol 25: 247-269

Daegling DJ (2001) Biomechanical scaling of the hominoid mandibular symphysis. J Morphol 250: 12-23

Daegling DJ (2002) Bone geometry in cercopithecoid mandibles. Archs Oral Biol 47: 315-325

Daegling D, Hotzman J (2003) Functional significance of cortical bone distribution in anthropoid mandibles: An in vitro assessment of bone strain under combined loads. Am J Phys Anthropol 122: 38-50

Davies HMS, McCarthy RN, Jeffcott LB (1993) Surface strain on the dorsal metacarpus of thoroughbreds at different speeds and gaits. Acta Anat: 148-153

Dechow PC, Hylander WL (2000) Elastic properties amd masticatory bone stress in the macaque mandible. Am J Phys Anthropol 112: 541-552

Demes B, Stern JTJ, Hausman MR, Larson SG, McLeod KJ, Rubin CT (1998) Patterns of strain in the macaque ulna during functional activity. Am J Phys Anthropol 106: 87-100

De Ricqles AJ (1975) On bone histology of fossil and living reptiles, with comments on its functional and evolutionary significance. In: d'A Bellairs A, Cox CB (Eds) Morphology and Biology of Reptiles. Academic Press: London, pp 123-149

Enlow DH (1969) The bone of reptiles. In: Gans C, d'A Bellairs A (Eds) Biology of the Reptilia: 1A. Academic Press: London, pp 45-80

Herring SE, Liu ZJ (2000) Loading of the temporomandibular joint: Anatomical and in vivo evidence from the bones. Cell Tiss Organs 169: 193-200

Herring SW, Rafferty KL, Liu ZJ, Marshall CD (2001) Jaw muscles and the skull in mammals: the biomechanics of mastication. Comp Biochem Physiol Part A: Mol Integrative Physiol 131: 207-219

Herring SW, Teng S (2000) Strain in the braincase and its sutures during function. Am J Phys Anthropol 112: 575-593

Herring SW, Teng S, Huang X, Mucci R, Freeman J (1996) Patterns of bone strain in the zygomatic arch. Anat Rec 246: 446455

Hibbeler RC (2000) Mechanics of Materials, Third Ed. Prentice Hall: Upper Saddle River, New Jersey

Hogue A, Ravosa MJ (2001) Transverse masticatory movements, occlusal orientation, and symphyseal fusion in selenodont artiodactyls. J Morphol 249: 221-241

Hsieh Y-F, Robling AG, Ambrosius WT, Burr D, Turner CH (2001) Mechanical loading of diaphyseal bone in vivo: the strain threshold for an osteogenic response varies with location. J Bone Miner Res 16: 2291-2297

Hylander WL (1979 a) Mandibular function in Galago crassicaudatus and Macaca fascicularis: An in vivo approach to stress analysis of the mandible. J Morphol 159: 253-296

Hylander WL (1979b) The functional significance of primate mandibular form. J Morphol 160: 223-240

Hylander WL (1985) Mandibular function and biomechanical stress and scaling. Am Zool 25: 315-330

Hylander WL (1988) Implications of in vivo experiments for interpreting the functional significance of "robust" australopithecine jaws. In: Grine FE (Ed) Evolutionary History of the "Robust" Australopithecines. Aldine de Gruyter, New York, pp 55-83

Hylander WL, Bays R (1979) In vivo strain gauge analysis of the dentary squamosal joint reaction force during mastication and incisal biting in Macaca mulatta and Macaca fascicularis. Archs Oral Biol 24: 689-697

Hylander WL, Johnson KR (1992) Strain gradients in the craniofacial region of primates. In: Davidovich Z (Ed) The Biological Mechanisms of Tooth Movement and Craniofacial Adaptation. Ohio State University: Columbus, Ohio, pp 559-569

Hylander WL, Johnson KR (1997) In vivo bone strain patterns in the zygomatic arch of macaques and the significance of these patterns for functional interpretations of craniofacial form. Am J Phys Anthropol 102: 203-232

Hylander WL, Ravosa MJ (1992) An analysis of the supraorbital region of primates: a morphometric and experimental approach. In: Smith P, Tchernov E (Eds) Structure, Function and Evolution of Teeth. Freund Publishing House Ltd: London, pp 223-255

Hylander WL, Picq PG, Johnson KR (1991) Function of the supraorbital region of primates. Archs Oral Biol 36: 273-281

Jenkins I, Thomason JJ, Norman DB (2002) Primates and engineering principles: applications to craniodental mechanisms in ancient terrestrial predators. Senckenbergiana lethaea 82: 223-240

Kakudo Y, Ishida A, Yoshimoto S (1973) Strains in the dog's jaw bones following implant insertion and a photoelestic study of implants and the jaw bones. J Osaka Dent Univ 7: 31-42

Lanyon LE, Goodship AE, Pye CJ, MacFie JH (1982) Mechanically adaptive bone remodelling. J Biomech 15: 141-154

Lieberman DE, Pearson OM, Polk JD, Demes B, Crompton AW (2003) Optimization of bone growth and remodeling in response to loading in tapered mammalian limbs. J Exp Biol 206: 3125-3138

Lieberman DE, Krovitz GE, Yates FW, Deulin M, St. Claire M (2004) Effects of food processing on masticatory strain and cramiofacial growth in a retrograthic face. J. hum. Evol 46: 647-789

Liu ZJ, Herring SE (2000a) Bone surface strains and internal bony pressures at the jaw joint of the miniature pig during masticatory muscle contraction. Archs Oral Biol 45: 95-112

Liu ZJ, Herring SE (2000 b) Masticatory strains on osseous and ligamentous components of the temporomandibular joint in miniature pigs. J Orofac Pain 14: 265-278

Moss ML, Young RW (1960) A functional approach to craniology. Am J Phys Anthropol 18: 281-292

Nunamaker DM, Butterweck DM, Provost MT (1990) Fatigue fractures in thoroughbred racehorses: relationships with age, peak bone strain and training. J Orthopaed Res 8: 604-611

Preuschoft H, Demes B, Meier M, Bär HF (1986) The biomechanical principles realised in the upper jaw of long-snouted primates. In: Else J, Lee PC (Eds) Primate Evolution. Cambridge University Press: Cambridge, pp 249-164 
Preuschoft H, Demes B, Meier M, Bär HF (1986) Les principes mécaniques réalisés dans la machoire supérieure des vertebrés a museau long. In: Sakka M (Ed) Définition et origines de l'homme. Edition CNRS: Paris, pp 177-202

Rafferty KL, Herring SE, Artese F (2000) Three-dimensional loading and growth of the zygomatic arch. J Exp Biol 203: 2093-3004

Ravosa MJ (1988) Browridge development in Cercopithecidae: A test of two models. Am J Phys Anthropol 76: 535-555

Ravosa MJ (1990) Functional assessment of subfamily variation in maxillomandibular morphology among Old World Monkeys. Am J Phys Anthropol 82: 199-212

Ravosa MJ (1991 a) Interspecific perspective on mechanical and nonmechanical models of primate circumorbital morphology. Am J Phys Anthropol 86: 369-396

Ravosa MJ (1991 b) Ontogenetic perspective on mechanical and non-mechanical models of primate circumorbital morphology. Am J Phys Anthropol 85: 95-112

Ravosa MJ (1991c) Structural allometry of the mandibular corpus and symphysis in prosimian primates. J Hum Evol 20: $3-20$

Ravosa MJ (1996) Mandibular form and function in North American and European Adapidae and Omomyidae. J Morphol 229: 171-190

Ravosa MJ, Johnson KR, Hylander WL (2000a) Strain in the galago facial skull. J Morphol 245: 51-66

Ravosa MJ, Noble VE, Hylander WL, Johnson KR, Kowalski EM (2000 b) Masticatory stress, orbital orientation and the evolution of the primate postorbital bar. J Hum Evol 38: 667693

Rayfield EJ, Norman DB, Horner CC, Horner JR, Smith PM, Thomason JJ, Upchurch P (2001) Cranial design and function in a large theropod dinosaur. Nature 409: 1033-1037

Ross CF (2001) In vivo function of the craniofacial haft: the interorbital "illar". Am J Phys Anthropol 116: 108-139
Ross C, Hylander WL (1996) In vivo and in vitro bone strain in owl monkey circumorbital region and the function of the postorbital septum. Am J Phys Anthropol 101: 183-215

Rybicki EF, Mills EJ, Turner AS, Simonen FA (1977) In vivo and analytical studies of forces and moments in equine long bones. J Biomech 10: 701-705

Shea BT (1986) Phylogeny and skull form in the hominoid primates. In: Schwartz JH (Ed) Orang-utan Biology. Oxford University Press: Oxford, pp 233-245

Thomason JJ (1991) Cranial strength in relation to estimated biting forces in some mammals. Can J Zool 69: 2326-2333

Thomason JJ, Grovum LE, Deswysen AG, Bignell WW (2001) In vivo surface strain and stereology of the frontal and maxillary bones of sheep: implications for the structural design of the mammalian skull. Anat Rec 264: 325-338

van Drongelen W, Dullemeijer P (1982) The feeding apparatus of Caiman crocodilus: a functional morphological study. Anat Anz 151: 337-366

Vinyard C, Ravosa MJ (1998) Ontogeny, function, and scaling of the mandibular symphysis in papionin primates. J Morphol 235: $157-175$

Weijs WA, De Jong JH (1977) Strain in mandibular alveolar bone during mastication in the rabbit. Archs Oral Biol 22: 667-675

Witzel U, Preuschoft H (1999) The bony roof of the nose in humans and other primates. Zool Anz 238: 103-115

Witzel U, Preuschoft H (2002) Function-dependent shape characteristics of the human skull. Anthropol Anz 60:113-135

Wolff JEA (1984) A theoretical approach to solve the chin problem. In: Chivers D, Wood B, Bilsborough A (Eds) Food Acquisition and Processing in Primates. Plenum Press: New York, pp 391-405

Accepted May 17, 2004 